\title{
Regulation of nutrient supply: the brain and appetite control
}

\author{
BY J. E. BLUNDELL AND J. C. G. HALFORD \\ Biopsychology Group, Psychology Department, University of Leeds, Leeds LS2 9JT
}

\begin{abstract}
The regulation of nutrient supply connotes a scientific interest in the control of food consumption since eating is the means through which the body (and brain) receives its supply of nutrients. In turn, the nutrient value of food is clearly one factor which plays a role in the pattern of food consumption. Therefore, investigations of the processes underlying appetite control should give some priority to the nutritional characteristics of the foods consumed. For approximately the last 20 years the study of the brain and appetite control has been driven, in part, by the need to understand the problem of human obesity and to develop strategies to treat or prevent the condition. In this context the regulation of nutrient supply assumes particular significance since a number of studies have indicated a positive relationship between the proportion of fat in the diet and the prevalence of overweight or obesity (e.g. Dreon et al. 1988; Romieu et al. 1988; Klesges et al. 1992; Tucker \& Kano, 1992). Consequently, there is an urgent need to examine neural mechanisms for the control of appetite with reference to the regulation of intake of dietary fat and the control of body weight.
\end{abstract}

\section{EATING BEHAVIOUR OR FUEL INTAKE?}

Food consumption is the target of scientific research for a number of different researchers including physiologists, nutritionists, psychologists, biochemists, endocrinologists and many others. All these researchers share, as one of their primary goals, the attempt to understand the mechanisms responsible for human food consumption. However, the terminology which refers to this end-point may appear discordant. For one group of researchers the phenomenon usually measured is called eating, human feeding or food intake. In other scientific domains the phenomenon is called dietary intake, energy intake or more commonly spontaneous energy intake. Differences are also apparent at the level of scientific practice. The first group is often concerned with qualitative aspects of eating such as food choice, preferences and the sensory aspects of food together with subjective phenomena such as hunger, fullness and hedonic sensations which accompany eating and which are sometimes regarded as causal agents. The second group is primarily concerned with quantitative aspects of consumption and with the energetic value of food; at the present time particular importance is attached to the macronutrient composition of food and its impact on energy balance.

It is not surprising that differing conceptual formulations have arisen from separate scientific disciplines with different ideologies. However, the identification of food consumption as either a form of behaviour or as fuel intake is not just a semantic issue and the study of human appetite should attempt to reconcile these different approaches. What is the relationship between the pattern of intake of meals and snacks (behavioural profile), the tastes and other sensory attributes of the foods consumed (qualitative pattern) and the total food consumed over a $24 \mathrm{~h}$ period (spontaneous energy intake) together with the proportions of macronutrients (fuel balance)? A consideration of the 
significance of dietary fat may serve to integrate different approaches. At the same time this will refocus attention onto the causes of weight gain and weight maintenance. Is obesity brought about by enhanced feelings of hunger, weakened satiety, sensorilyinduced overconsumption or hedonically-mediated maladaptive food choices? Or is obesity a result of errors in processes governing energy balance, inappropriate oxidation of fuels or different metabolic responses to varying dietary intakes?

\section{A BIO-BEHAVIOURAL SYSTEM: REGULATION AND ADAPTATION}

Food intake has an ambiguous status as a scientific variable. On one hand it can be regarded as a biological phenomenon (as an expression of biological needs) with socio-cultural implications (symbolic role in cuisine and important features of cultural life). On the other hand food intake can be regarded as a social phenomenon which has biological consequences. These views draw attention to the interactionist view of food consumption (Blundell, 1984; Blundell \& Hill, 1986) and illustrate how eating represents a transaction between biological and environmental domains. Consequently, food intake (and the nutrient supply) is an outcome influenced by biological and environmental forces. Nutritional intake plays an obvious role in homeostatic processes which serve the purpose of biological regulation but, as a form of behaviour, nutrient intake is also adapted to particular environmental demands (see Fig. 1). This interplay between biological demands and environmental requirements has implications for the regulation of body weight and also draws attention to key principles which govern the operation of this bio-behavioural system.

A consideration of anthropological, epidemiological and experimental evidence suggests that it is easier for human beings to gain weight than to reduce weight. This implies that the control of appetite (by the psychobiological system) is asymmetrical rather than symmetrical. Fig. 1 illustrates a simple conceptualization of how this arises. The extension of Claude Bernard's principle of homeostasis to include behaviour is often referred to as the behavioural regulation of internal states (Richter, 1943). Logic demands that behaviour (eating) is controlled in accordance with biological states of need. This constitutes a form of biological regulation. However, the expression of behaviour is also subject to environmental demands, and behaviour is adapted in the face of particular circumstances. In the case of human appetite, consideration should be given to the conscious and deliberate control over eating behaviour. Human beings can decide to alter their own behaviour (in this case, eating) in order to meet particular objectives, for example, a display of moral conviction (political hunger strike) or a demonstration of aesthetic achievement (e.g. dieting). In both of these examples eating is curtailed with an ensuing interruption or depletion of the nutritional supply. Regulatory mechanisms will tend to oppose this undersupply and generate a drive to eat. In many parts of the world environmental adaptation also means adjusting to a food supply characterized by an abundance of palatable, energy-dense (mainly high-fat) foods or by a large proportion of fatty items. Exposure to these types of diets usually gives rise to an overconsumption of energy. Since this does not appear to be biologically driven (by a need state) or consciously intended this phenomenon can be referred to as passive overconsumption. This, in turn, is an interaction with genetic vulnerability which leads to an increase in fat deposition (Bouchard, 1985). This is exemplified in the changes in dietary habits that have led to increased incidence of obesity among inhabitants of Polynesia and 


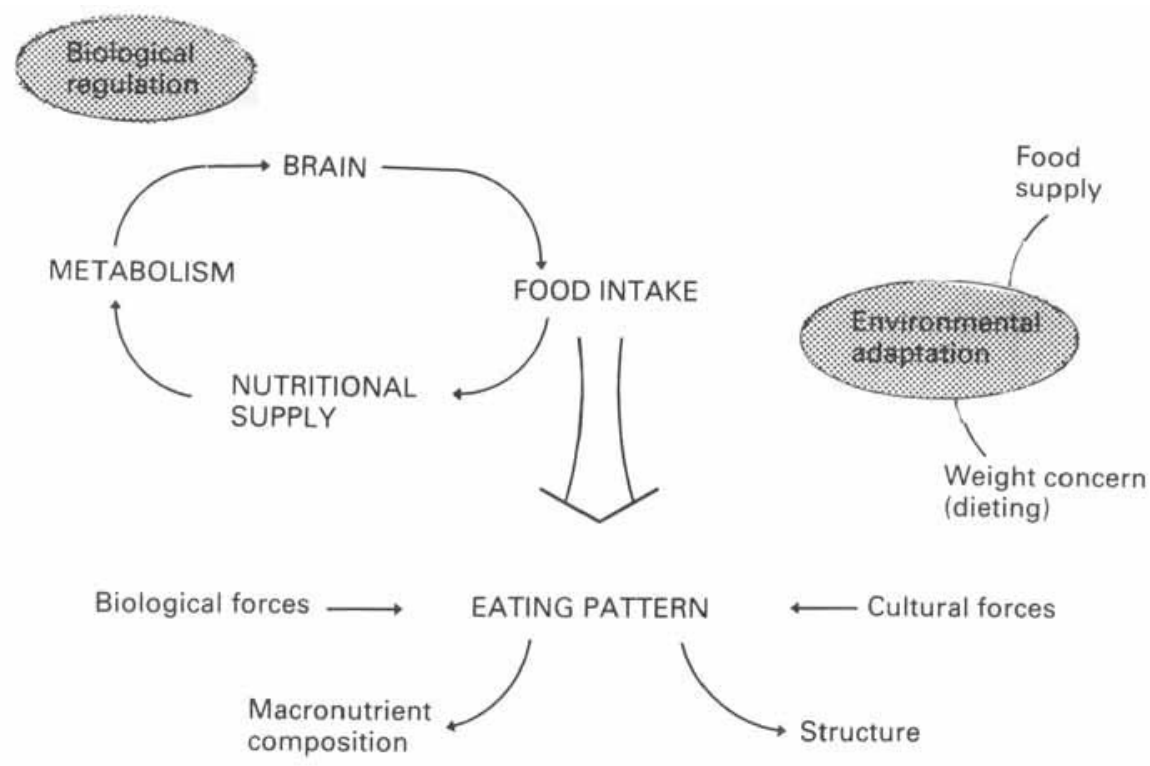

Fig. 1. Schematic diagram to illustrate that the pattern of eating behaviour arises from an interaction between biological regulation and environmental adaptation. Eating is a product of both biology and culture.

Micronesia (Zimmet, 1992). In these islands fat makes the biggest contribution to the high energy content of the diet and, therefore, has the biggest impact on overconsumption.

However, this passive overconsumption leading to the accumulation of body fat does not appear to generate any biological drive to undereat. Obese people do not get any help from their adipose tissue to reduce their appetites. Hence, the operation of the regulatory system is not symmetrical. Two principles may be deduced. First, that biological processes exert a strong defence against undereating which serves to protect the body from an energy (nutritional) deficit. Therefore, undereating must normally be an active and deliberate process. Second, in general, biological defences against overconsumption are weak or inadequate. This means that overeating may occur despite the best efforts of people to prevent it. In contrast to undereating (dieting, fasting), overeating can be a passive process.

In considering the regulation of nutrient supply and the neural control of appetite, it is important to keep in mind the interaction between biological and environmental influences and the principles which appear to govern the operation of the biobehavioural system.

\section{APPETITE CONTROL AND THE SATIETY CASCADE}

How does the appetite control system operate to reflect these regulation and control processes? One way to think about this issue is to consider how eating behaviour is held in place by the interaction between the characteristics of food and the biological responses to ingestion. These biological responses are often thought of as 'satiety signals'. Several characteristics of ingested food must be monitored, including taste 


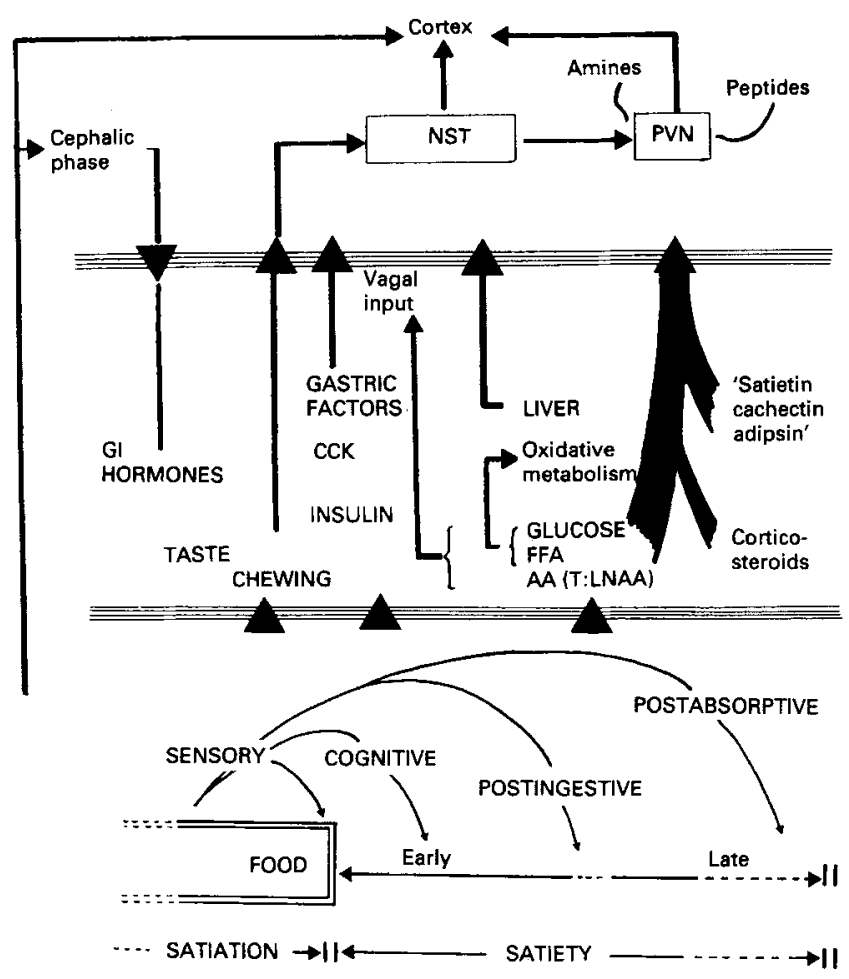

Fig. 2. Diagram showing the expression of appetite as the relationship between three levels of operations: behaviour, peripheral physiology and metabolism, and brain activity. GI, gastrointestinal; CCK, cholecystokinin; FFA, non-esterified fatty acids; AA, amino acids; T:LNAA, tryptophan:large neutral amino acids; NTS, nucleus of the tractus solitarius; PVN, paraventricular nucleus.

(intensity and hedonic aspects), volume and weight, energy density, osmolarity and the proportion of macronutrients. Biological responses generated include oral afferent stimulation, stomach distension, rate of gastric emptying, release of hormones such as cholecystokinin and insulin, triggering of digestive enzymes (and co-factors) and plasma profiles of glucose, amino acids and other metabolites. The organization of this activity can be conceptualized in the form of a cascade (Fig. 2, lower section). Two features are worth considering. First, the distinction between satiation and satiety. Satiation refers to the processes which bring a period of eating to an end and this activity, therefore, influences the size of meals and snacks. Satiety refers to the inhibition of hunger and further eating which arises as a consequence of food ingestion. These two processes, therefore, control events going on within-meals or between-meals. Second, the potency of the mediating processes of the cascade and particularly the relative strength of postingestive (but pre-absorptive) and postabsorptive mechanisms. It is clearly the properties of food (and the act of ingesting it) which trigger the initiation of the overlapping physiological responses. The amount (quantity) and nature (quality) of the food will determine the intensity and time-course of the biological processes generated. This situation reflects the idea of the differential satiating power of different types of food (e.g. Kissileff et al. 1984). 


\section{STRUCTURE OF THE BIO-BEHAVIOURAL CONTROL SYSTEM}

The system can be conceptualized on three levels (see Fig. 2). These are the levels of psychological events (hunger perception, cravings, hedonic sensations) and behavioural operations (meals, snacks, energy and macronutrient intakes); the level of peripheral physiology and metabolic events; and the level of neurotransmitter and metabolic interactions in the brain (see Blundell, 1991a). Appetite reflects the synchronous operation of events and processes in the three levels. Neural events trigger and guide behaviour, but each act of behaviour involves a response in the peripheral physiological system; in turn, these physiological events are translated into brain neurochemical activity. This brain activity represents the strength of motivation and the willingness to refrain from feeding.

Even before food touches the mouth, physiological signals are generated by the sight and smell of food. These events constitute the cephalic phase of appetite (Powley, 1977). Cephalic-phase responses are generated in many parts of the gastrointestinal tract; their function is to anticipate the ingestion of food. During and immediately after eating, afferent information provides the major control over appetite. It has been noted that 'afferent information from ingested food acting in the mouth provides primarily positive feedback for eating; that from the stomach and small intestine is primarily negative feedback' (Smith et al. 1990). Initially the brain is informed about the amount of food ingested and its nutrient content via afferent input. The gastrointestinal tract is equipped with specialized chemo- and mechanoreceptors that monitor physiological activity and pass information to the brain mainly via the vagus nerve (Mei, 1985). This afferent information constitutes one class of 'satiety signals' and forms part of the postingestive control of appetite. It is usual to identify a postabsorptive phase that arises when nutrients have undergone digestion and have crossed the intestinal wall to enter the circulation. These products, which accurately reflect the food consumed, may be metabolized in the peripheral tissues or organs or may enter the brain directly via the circulation. In either case, these products constitute a further class of metabolic satiety signals. Additionally, products of digestion and agents responsible for their metabolism may reach the brain and bind to specific chemoreceptors, influence neurotransmitter synthesis or alter some aspect of neuronal metabolism. In each case the brain is informed about some aspects of the metabolic state resulting from food consumption.

Traditional views of the neural control of appetite have been based on opposed hunger and satiety centres in the hypothalamus. These concepts are now out of date. A large number of neurotransmitters, neuromodulators, pathways and receptors are implicated in the central processing of information relevant to appetite. The profile of this activity reflects the flux of physiological and biochemical transactions in the periphery and represents the pattern of behavioural events and associated motivational states.

\section{NUTRITION AND THE PSYCHOBIOLOGICAL SYSTEM}

A vulnerable point within the psychobiological system is the interaction between the nature of the diet and the body's biological responses to food (Blundell, 1991a). The concept of the satiety cascade implies that foods of varying nutritional composition will engage differently with the mediating processes and, therefore, will exert differing effects on satiation and satiety. Dietary variables could overcome appetite control by a 
strong attractiveness mediated by sensory mechanisms, by nutrient composition (energy density) or by an interaction between sensory and nutritional components.

It is clear that when food modifies the expression of appetite, several characteristics of the ingested food may be monitored. These include taste (intensity and hedonics), volume and/or weight of food, energy density, osmolarity and the presence of different proportions of macronutrients. Biological responses generated by the monitoring of these components include oral afferent stimulation, gastric distension, rate of gastric emptying, release of hormones, triggering of digestive enzymes and plasma profiles of metabolized products. Some of these mechanisms have been described previously (Blundell, 1991b) and they constitute different classes of satiety signals.

\section{NUTRIENTS AND SATIETY}

One key issue involves the relative potency of the macronutrients protein, carbohydrate and fat to induce satiety and to control the expression of appetite. A consideration of the secular trends in the daily intake of macronutrients in Western Europe over the last 100 years or so indicates that protein intake has remained fairly constant at between 11 and $14 \%$ of daily food energy. This has occurred despite large fluctuations in the availability of protein suggesting that the intake of protein is tightly controlled. This is consistent with the generally accepted potent effect of protein on satiety (e.g. Hill \& Blundell, 1986; De Castro, 1987). However, it is noticeable that in many parts of Europe and North America large shifts in the daily consumption of fats and carbohydrates have taken place over the course of the present century. Generally speaking, carbohydrate intake has fallen whilst fat intake has increased. It is widely recognized that the current fat consumption of about $40 \%$ of daily food energy is too high and is contributing to a number of biological conditions including obesity.

How does this daily intake of carbohydrate and fat relate to the influence of these two macronutrients on satiety and modulation of the expression of appetite? For carbohydrate it has been argued on the basis of experiments on rats, that if the cumulative inhibitory effects of carbohydrate on feeding are indeed energostatic... then any substance which can readily be used by the animal to provide energy should produce an appropriate food intake compensation over a period of several hours after loading' (Booth, 1972). Studies have shown that this is also the case in humans. A variety of carbohydrates including glucose, fructose, sucrose, maltodextrins and polysaccharides exert measurable effects when given in a preload or an experimental meal. That is, they suppress later intake by an amount roughly equivalent to their energy content (Rogers \& Blundell, 1989), although the time-course of the suppressive action may vary according to the rate at which the carbohydrates are metabolized (Van Amelsvoort \& Weststrate, 1992).

Considering the regulation of carbohydrate by the brain, a number of possibilities are based on the glucostatic concept (Van Itallie, 1990). As Carlson (1991) has pointed out .. . 'because the brain controls eating, it seems reasonable that hunger might be triggered by a decrease in the brain's primary fuel'. The idea that the metabolism of glucose in the body is related to the existence of hunger and eating is represented by the glucostatic hypothesis formulated by Mayer (1953). The relationship between energy intake and glucose could be mediated via arterio-venous glucose differences, the rate of glucose utilization in the liver or the activation of glucoreceptive (glucosensitive) neurons 
in the brain. Neural pathways sensitive to changes in glucose oxidation have begun to be mapped (see Ritter \& Calangasan, 1994). There is also evidence for a link between neuropeptide Y (NPY)-containing neurons and carbohydrate metabolism (Leibowitz, 1989) and for a bio-behavioural link involving dietary carbohydrate and brain serotonin synthesis (Fernstrom \& Wurtman, 1971).

\section{FAT-RELATED SATIETY SIGNALS}

At the present time there is particular interest in the monitoring of dietary fat and in the effect of fat on satiety. Recent research has now confirmed the status of CCK as a hormone that mediates satiation and early-phase satiety. The consumption of protein or fat stimulates the release of CCK, which activates CCK-A receptors in the pyloric region of the stomach. This signal is transmitted via vagal afferents to the nucleus of the tractus solitarius, where it is relayed to the medial zones of the hypothalamus including the paraventricular nucleus (PVN) and ventromedial hypothalamus. The anorectic effect of systemically administered CCK can be blocked by vagotomy (Smith et al. 1985) and by the selective CCK-A receptor antagonist, Devazepide (MK-329) (Dourish et al. 1988). Significantly, there now exist many reports demonstrating that the CCK-A type antagonist administered alone leads to an increase in food intake in experimental animals (Hewson et al. 1988). Interestingly, trypsin inhibitors that block the inactivation of CCK produce a suppression of food intake in animals (McLaughlin et al. 1983) and humans (Hill et al. 1990). More recently the existence of a serotonin link in the mediation of CCK satiety has been proposed (Cooper et al. 1990) and this probably depends on receptors of the 5-hydroxytryptamine (5-HT) $1 \mathrm{c}$ subtype (Poeschla et al. 1993). Metergoline (a 5-HT receptor antagonist) attenuates CCK-induced anorexia whilst Devazepide antagonizes 5-HT-induced inhibition of feeding (Grignaschi et al. 1993). These mechanisms indicate ways in which the ingestion of dietary fat could trigger neurochemical responses which mediate satiety.

A further route by which dietary fat could induce a behavioural response is via enzyme systems responsible for the digestion of fat, in particular, pancreatic procolipase, a cofactor for lipase (EC 3.1.1.3), necessary for optimal fat digestion in the intestine during a meal. It is activated in the intestine by trypsin which cleaves the 100 amino acid procolipase to produce colipase and release of an activation peptide with the sequence Val-Pro-Asp-Pro-Arg in the rat. This activation peptide, known as VPDPR or enterostatin, decreases food intake in rats (Erlanson-Albertsson \& Larsson, 1988). Moreover, enterostatin appeared to selectively reduce intake of a high-fat diet (ErlansonAlbertsson et al. 1991). More recently enterostatin, now with the suggested structure Val-Pro-Gly-Pro-Arg, is increased after high-fat feeding and following the administration of CCK-8 (Mei et al. 1993). These findings suggest ways in which peripheral satiety signals could be generated by fat consumption.

A further class of 'satiety signals' is believed to arise during the absorptive or postabsorptive phase of nutrient handling. The products of food digestion may be metabolized in peripheral tissues or organs, or may enter the brain directly. It has been argued that the degree of oxidative metabolism of glucose and free fatty acids in the liver constitutes a significant source of information useful for the control of appetite (Friedman et al. 1986). Considering oxidative metabolism as a satiety signal for fat it is important to recognize that, according to this hypothesis, the oxidative signal could arise 
from the metabolism of ingested fat or from fuels derived from internal adipose stores (Friedman, 1990). Experimental evidence indicates that inhibition of fat oxidation by methyl palmoxirate (Friedman \& Tordoff, 1986) or 2-mercapto acetate (Langhans \& Scharrer, 1987) causes an increase in feeding. It is proposed that the oxidation of fat constitutes a signal for the suppression of eating. It follows that any suppression of appetite arising from this mechanism need not be tightly synchronized with the ingestion of fat.

In principle many products of digestion, and peptide fragments that activate their metabolizing enzymes, may bind to specific chemoreceptors or alter some aspect of neuronal metabolism. In each case the brain is informed about some aspect of the metabolic state resulting from food consumption. One interesting possibility concerns the glycoprotein apolipoprotein A-IV which is produced exclusively by the human small intestine (Sherman \& Weinberg, 1988); its output into intestinal lymph increases as a result of feeding fat (e.g. Hayashi et al. 1990) and in rats, intravenous administration of apolipoprotein A-IV decreases meal size (Fujimoto et al. 1993). It has been proposed that apolipoprotein A-IV constitutes a physiological signal for satiation after the consumption of fat (Fujimoto et al. 1992). Although the level of apolipoprotein A-IV responds to dietary fat manipulations in humans, its potential as a metabolic signal may be weakened by the observation that concentrations are subject to a rapidly acting autoregulatory mechanism (Weinberg et al. 1990).

One further source of peripheral satiety signals is the blood which has been proposed to carry specific substances reflecting the state of depletion or repletion of energy reserves and which directly modulate critical brain mechanisms. These substances include satietin (Knoll, 1979), adipsin (Cook \& Spiegelman, 1987), which is now thought more likely to be a regulator of fat metabolism than appetite, and the sugar acids, 3,4-dihydroxybutanoic acid- $\epsilon$-lactone, 2-buten-4-olide, and 2,4,5-trihydroxy pentanoic acid- $\gamma$-lactone (Oomura, 1988). In addition it has been reported that an anorectic factor has been extracted from the adipose tissue of overfed rats (Hulsey \& Martin, 1992). From an evolutionary perspective it is possible that many peripheral regulators of the handling of ingested nutrients could be exploited as potential signals of food-related activities or bodily needs.

\section{CENTRAL INFLUENCES ON APPETITE}

The influence of central neurochemical activity on the expression of appetite is complex. It involves numerous interactions between different loci and different receptors which result in shifts in the magnitude, direction and quality of eating behaviour. Much information has been accumulated from the direct application of chemicals to the brain either via the cerebrospinal fluid or directly into specific sites. Most agents suppress intake but a significant number stimulate eating, sometimes in a dramatic fashion (see Blundell, 1991 b). The most frequently demonstrated action is the stimulation of feeding following activation of $\alpha_{2}$-adrenoceptors in the PVN (Leibowitz, 1978). It is also known that spontaneous feeding is associated with endogenous release of noradrenaline in the PVN, and with an increase in PVN $\alpha_{2}$-adrenoceptor density (Leibowitz, 1988). The PVN also contains glucosensitive neurons and, therefore, may be a point of interaction for neurotransmitter activity and metabolic states reflecting energy regulation. Circulating corticosteroids influence $\alpha_{2}$-adrenoceptor sensitivity and it has been argued that 
noradrenaline and 5-HT act antagonistically to influence the release of corticotrophinreleasing factor (CRF). Since the $\mathrm{PVN}$ is also a potent anorectic drug-binding site (Angel, 1990), neurochemical activity in this area may serve to integrate behavioural, metabolic and neuroendocrine responses. In more lateral areas of the hypothalamus (perifornical zone) feeding is suppressed by micro-injection of agents that activate dopamine $D_{2}$ receptors or $\beta_{2}$-adrenoceptors (Leibowitz \& Brown, 1980). Consequently noradrenaline, 5-HT and dopamine acting at closely related sites in the hypothalamus produce quantitative shifts in feeding.

Potent feeding responses can also be obtained by micro-injection of peptides to the brain. Many peptides such as insulin, CCK, calcitonin, bombesin, neurotensin, thyroidhormone-releasing hormone, somatostatin, vasoactive intestinal polypeptide, CRF and glucagon suppress feeding after cerebroventricular administration. A smaller number of peptides, including $\beta$-endorphin, dynorphin, NPY, peptide YY and galanin, increase food intake. When injected into the PVN, NPY and PYY can induce rats to eat $50 \%$ of their normal daily food intake within $1 \mathrm{~h}$. The stimulation of feeding by galanin appears to be specific to the PVN and closely related sites. Classic research of a decade ago indicated how projections between the brainstem and hypothalamic nuclei were involved in neuroendocrine regulation. This pattern of projections is also important for feeding; peptides such as NPY and galanin appear to originate (in part) in adrenergic ( $\mathrm{C} 1, \mathrm{C} 2)$ or noradrenergic (A1, A2, A6) nuclei in the brainstem. Thus, various peptides and monoamines appear to act in concert to influence the organization of expression of appetite (and energy balance more generally). These actions are generated in response to visceral and metabolic information which reflects the immediate past history of feeding and the body's nutritional status.

The peptide, galanin, which controls feeding, when injected into PVN (Kyrkouli et al. 1990) may be particularly important in the control of fat intake. Initially, it was shown that galanin, like NPY, promoted carbohydrate intake while having no effect on protein intake (Temple et al. 1988). However, it was recognized also that galanin had a stimulatory effect on fat intake which was particularly strong at the end of the nocturnal cycle (Leibowitz, 1989). These findings raise the possibility that there is a specific fat-seeking system in the brain which could mediate in a biological drive for dietary fat. In addition, galanin may be implicated in the vagal component of the pathway through which eating is initiated following blockade of fat oxidation by 2-mercapto acetate (Ritter \& Calangasan, 1994).

\section{THE FAT PARADOX: FAT-INDUCED SATIETY SIGNALS AND HIGH-FAT HYPERPHAGIA}

Infusion of maize oil into the intestine inhibits hunger and slows the rate of gastric emptying (Welch et al. 1985). However, Intralipid infused intravenously has no inhibitory effect on appetite. Similar effects have been demonstrated in rats (Greenberg et al. 1989). Moreover, the inhibitory action of intestinal Intralipid can be blocked by lorglumide, an antagonist of CCK-A-type receptors (Greenberg et al. 1992). Taken together these studies suggest that fat in the intestine generates potent pre-absorptive satiety signals which are mediated, at least in part, by a CCK mechanism. However, when rats are placed on high-fat diets or given fat supplements they take in excessive amounts of energy and rapidly gain weight. Moreover, human subjects exposed to a 
range of high-fat foods also increase their energy intake and gain weight compared with subjects eating a medium- or low-fat diet. In addition high-fat foods markedly increase meal size (measured in terms of energy) and this effect is particularly marked in obese subjects (Lawton et al. 1993). What is the explanation for the apparent contradiction between fat-induced satiety signals and the easy overconsumption of high-fat foods?

Although emulsified fat delivered to the intestine (duodenum or jejunum) produces prompt satiety signals, consumed fat will take some time to reach the intestine in similar form and its action is likely to be diluted by other nutrients. Hence, consumed fat may engender more slowly arising satiety signals. Two features of fat favour the rapid consumption of energy. First, fat produces potent oral stimulation which facilitates intake; second, high-fat foods normally have a high energy density. This means that a large amount of fat energy can be consumed before fat-induced satiety signals become operative. The signals are apparently too weak or too delayed to prevent the intake of a large amount of energy. One of the consequences of a food supply containing readily available, very palatable high-fat foods is that the natural fat-induced satiety mechanism becomes overwhelmed.

This situation provides a good example of the interaction of biological and environmental influences on the expression of appetite. Here, it appears that certain physiological processes (gastrointestinal satiety mechanisms) are not sufficiently strong to prevent the consumption of fat which is promoted through facilitatory oro-sensory mechanisms in combination with a fat-rich, energy-dense environmental food supply. Consequently, in considering the overall control of food intake, it is necessary to recognize the existence of neural systems which influence eating behaviour. However, the normal operation of these systems does not guarantee a control over food intake so as to prevent the occurrence of a positive energy balance. Through the course of evolution brain mechanisms (detecting peripheral signals) have developed so as to ensure an adequate food intake but they do not prevent overconsumption, particularly when energy expenditure is very low. This perspective should be considered when evaluating strategies to deal with the escalating problem of overweight in many affluent societies.

\section{REFERENCES}

Angel, I. (1990). Central receptors and recognition sites mediating the effects of monoamines and anorectic drugs on feeding behaviour. Clinical Neuropharmacology 13, 361-391.

Blundell, J. E. (1984). Systems and interactions: An approach to the pharmacology of eating and hunger. In Eating and its Disorders, pp. 39-65 [A. J. Stunkard and E. Stellar, editors]. New York: Raven Press.

Blundell, J. E. (1991a). The biology of appetite. Clinics in Applied Nutrition 1, 21-31.

Blundell, J. E. (1991b). Pharmacological approaches to appetite suppression. Trends in Pharmacological Sciences 12, 147-157.

Blundell, J. E. \& Hill, A. J. (1986). Biopsychological interactions underlying the study and treatment of obesity. In The Psychosomatic Approach: Contemporary Practice of Whole Person Care, pp. 115-138 [M. J. Christie and P. G. Mellett, editors]. Chichester: Wiley.

Booth, D. A. (1972). Postabsorptively induced suppression of appetite and the energostatic control of feeding. Physiology and Behaviour 9, 199-202.

Bouchard, C. (1985). Inheritance of fat distribution and adipose tissue metabolism. In Metabolic Complications of Human Obesities, pp. 87-96 [J. Vague, P. Bjorntorp, B. Guy-Grand, M. Rebuffe-Scrive and P. Vague, editors]. Amsterdam: Excerpta Medica.

Carlson, N. R. (1991). Physiology of Behaviour, 5th ed., pp. 411, 714. Boston: Allyn \& Bacon.

Cook, K. S. \& Spiegelman, B. M. (1987). Adipsin, a circulating serine protease homolog secreted by adipose tissue and sciatic nerve. Science 237, 402-404. 
Cooper, S. J., Dourish, C. T. \& Barber, D. J. (1990). Reversal of the anorectic effect of $(+)$ fenfluramine in the rat by the selective cholecystokinin antagonist MK-329. British Journal of Pharmacology 99, 65-70.

De Castro, J. M. (1987). Macronutrient relationship with meal patterns and mood in the spontaneous feeding behaviour of humans. Physiology and Behaviour 39, 561-569.

Dourish, C. T., Coughlan, J., Hawley, D., Clark, M. \& Iversen, S. D. (1988). Blockade of CCK-induced hypophagia and prevention of morphine tolerance by the CCK antagonist L-364,718. In CCK Antagonists, pp. 307-325 [R. Y. Wang and R. Schoenfeld, editors]. New York: Alan R. Liss Inc.

Dreon, D. M., Frey-Hewitt, B., Ellsworth, N., Williams, P. T., Terry, R. B. \& Wood, P. D. (1988). Dietary fat: carbohydrate ratio and obesity in middle aged men. American Journal of Clinical Nutrition 47, 995-1000.

Erlanson-Albertsson, C. \& Larsson, A. (1988). The activation peptide of pancreatic procolipase decreases food intake in rats. Regulatory Peptides 22, 325-331.

Erlanson-Albertsson, C., Mei, J., Okada, S., York, D. \& Bray, G. A. (1991). Pancreatic procolipase propeptide, Enterostatin, specifically inhibits fat intake. Physiology and Behaviour 49, 1191-1194.

Fernstrom, J. D. \& Wurtman, R. J. (1971). Brain serotonin content: increase following ingestion of carbohydrate diet. Science 174, 1023-1025.

Friedman, M. I. (1990). Body fat and the metabolic control of food intake. International Journal of Obesity 14, Suppl. 3, 53-67.

Friedman, M. I. (1991). Metabolic control of calorie intake. In Chemical Senses. vol. 4, Appetite and Nutrition, pp. 19-38 [M. I. Friedman, M. G. Tordoff and M. K. Kare, editors]. New York: Marcel Dekker Inc.

Friedman, M. I. \& Tordoff, M. G. (1986). Fatty acid oxidation and glucose utilization interact to control food intake in rats. American Journal of Physiology 251, R840-R847.

Friedman, M. I., Tordoff, M. G. \& Ramirez, I. (1986). Integrated metabolic control of food intake. Brain Research Bulletin 17, 855-859.

Fujimoto, K., Cardelli, J. A. \& Tso, P. (1992). Increased apolipoprotein A-IV in rat mesenteric lymph after lipid meal acts as a physiological signal for satiation. American Journal of Physiology 262, G1002-G1006.

Fujimoto, K., Machidori, H., Iwakiri, R., Yamamoto, K., Fujisaki, J., Sakata, T. \& Tso, P. (1993). Effect of intravenous administration of apolipoprotein A-IV on patterns of feeding, drinking and ambulatory activity of rats. Brain Research 608, 233-237.

Greenberg, D., Smith, G. P. \& Gibbs, J. (1992). Cholecystokinin and the satiating effect of fat. Gastroenterology 102, 1801-1812.

Greenberg, D., Torres, N. I., Smith, G. P. \& Gibbs, J. (1989). The satiating effect of fats is attenuated by the cholecystokinin antagonist lorglumide. Annals of the New York Academy of Sciences 575, 517-520.

Grignaschi, G., Mantelli, B., Fracasso, C., Anelli, M., Caccia, S. \& Samanin, R. (1993). Reciprocal interaction of 5-hydroxytryptamine and cholecystokinin in the control of feeding patterns in rats. British Journal of Pharmacology 109, 491-494.

Hayashi, H., Nutting, D. F., Fujimoto, K., Cardelli, J. A., Black, D. \& Tso, P. (1990). Transport of lipid and apolipoproteins A-I and A-IV in intestinal lymph of the rat. Journal of Lipid Research 31, 1613-1625.

Hewson, G., Leighton, G. E., Hill, R. G. \& Hughes, J. (1988). The cholecystokinin receptor antagonist $\mathrm{L} 364,718$ increases food intake in the rat by attenuation of the action of endogenous cholecystokinin. British Journal of Pharmacology 93, 79-84.

Hill, A. J. \& Blundell, J. E. (1986). Macro-nutrients and satiety: the effects of a high protein or a high carbohydrate meal on subjective motivation to eat and food preferences. Nutrition and Behaviour 3, $133-144$.

Hill, A. J., Peikin, S. R., Ryan, C. A. \& Blundell, J. E. (1990). Oral administration of proteinase inhibitor II from potatoes reduces energy intake in man. Physiology and Behaviour 48, 241-246.

Hulsey, M. G. \& Martin, R. J. (1992). An anorectic agent from adipose tissue of overfed rats: effects on feeding behaviour. Physiology and Behaviour 52, 1141-1149.

Kissileff, H. R., Gruss, L. P., Thornton, J. \& Jordan, H. A. (1984). The satiating efficiency of foods. Physiology and Behaviour 32, 319-332.

Klesges, R. C., Klesges, L. M., Haddock, C. K. \& Eck, L. H. (1992). A longitudinal anaylsis of the impact of dietary intake and physical activity on weight change in adults. American Journal of Clinical Nutrition 55, 818-822.

Knoll, J. (1979). Satietin: a highly potent anorexigenic substance in human serum. Physiology and Behaviour $23,497-502$.

Kyrkouli, S. E., Stanley, G. B., Seirafi, R. D. \& Leibowitz, S. F. (1990). Stimulation of feeding by galanin: anatomical localization and behavioural specificity of this peptide's effects in the brain. Peptides 11, 995-1001. 
Langhans, W. \& Scharrer, E. (1987). Evidence for a vagally mediated satiety signal derived from hepatic fatty acid oxidation. Journal of the Autonomous Nervous System 18, 13-21.

Lawton, C. L., Burley, V. J., Wales, J. K. \& Blundell, J. E. (1993). Dietary fat and appetite control in obese subjects: weak effects on satiation and satiety. International Journal of Obesity 17, 409-416.

Leibowitz, S. F. (1978). Paraventricular nucleus: a primary site mediating adrenergic stimulation of feeding and drinking. Pharmacology Biochemistry Behaviour 8, 163-175.

Leibowitz, S. F. (1988). Hypothalamic paraventricular nucleus: interaction between $\alpha_{2}$-noradrenergic system and circulating hormones and nutrients in relation to energy balance. Neuroscience Biobehaviour Review 12, 101-109.

Leibowitz, S. F. (1989). Hypothalamic neuropeptide Y, Galanin and Amines: concepts of coexistence in relation to feeding behaviour. Annals of the New York Academy of Sciences 575, 221-235.

Leibowitz, S. F. \& Brown, L. L. (1980). Histochemical and pharmacological analysis of noradrenergic projections to the paraventricular hypothalamus in relation to feeding stimulation. Brain Research 201, 289-314.

McLaughlin, C. L., Peikin, S. R. \& Baile, C. A. (1983). Trypsin inhibitor effects on food intake and weight gain in Zucker rats. Physiology and Behaviour 31, 241-246.

Mayer, J. (1953). Glucostatic mechanism of the regulation of food intake. New England Journal of Medicine 249, 13-16.

Mei, J., Bowyer, R. C., Jehanli, A. M. T., Patel, G. \& Erlanson-Albertsson, C. (1993). Identification of enterostatin, the pancreatic procolipase activation peptide in the intestine of rat: effect of CCK- 8 and high fat feeding. Pancreas 8, 488-493.

Mei, N. (1985). Intestinal chemosensitivity. Physiology Review 65, 211-237.

Oomura, Y. (1988). Chemical and neural control of feeding motivation. Physiology and Behaviour 44, 555-560.

Poeschla, B., Gibbs, J., Simansky, K. J., Greenberg, D. \& Smith, G. P. (1993). Cholecystokin-induced satiety depends on activation of 5-HT $1 \mathrm{C}$ receptors. American Journal of Physiology 264, R62-R64.

Powley, J. (1977). The ventromedial hypothalamic syndrome, satiety and a cephalic phase hypothesis. Psychological Review 84, 89-126.

Richter, C. P. (1943). Total self-regulatory functions in animals and human beings. Harvey Lecture Series 38, 63-103.

Ritter, S. \& Calangasan, N. Y. (1994). Neural substrates for metabolic controls of feeding. In Appetite and Body Weight Regulation. Sugar, Fat and Macronutrient Substitutes, pp. 77-94 [J. D. Fernstrom and G. D. Miller, editors]. Boca Raton: CRC Press.

Rogers, P. J. \& Blundell, J. E. (1989). Separating the actions of sweetness and calories: effect of saccharin and carbohydrates on hunger and food intake in human subjects. Physiology and Behaviour 45, 1093-1099.

Romieu, I., Willett, W., Stampfer, M. J., Colditz, G. A., Sampson, L., Rossner, B., Hennekens, C. H. \& Speizer, F. E. (1988). Energy intake and other determinants of relative weight. American Journal of Clinical Nutrition 47, 406-412.

Sherman, J. R. \& Weinberg, R. B. (1988). Serum apolipoprotein A-IV and lipoprotein cholesterol in patients undergoing total parental nutrition. Gastroenterology 95, 394-401.

Smith, G. P., Greenberg, D., Corp, E. \& Gibbs, J. (1990). Afferent information in the control of eating. In Obesity: Towards a Molecular Approach, pp. 63-79 [G. A. Bray, editor]. New York: Alan R. Liss.

Smith, G. P., Jerome, C. \& Norgren, R. (1985). Afferent axons in abdominal vagus mediate satiety effect of cholecystokinin in rats. American Journal of Physiology 249, R638-R641.

Temple, D. L., Leibowitz, K. J. \& Leibowitz, S. F. (1988). Effects of PVN galanin on macronutrient selection. Peptides 9, 309-314.

Tucker, L. A. \& Kano, M. J. (1992). Dietary fat and body fat: a multivariate study of 205 adult females. American Journal of Clinical Nutrition 56, 616-622.

Van Amelsvoort, J. M. M. \& Weststrate, J. A. (1992). Amylose-amylopectin ratio in a meal affects postprandial variables in male volunteers. American Journal of Clinical Nutrition 55, 712-718.

Van Itallie, T. B. (1990). The glucostatic theory 1953-1988: roots and branches. International Journal of Obesity 14, Suppl. 3, 1-10.

Weinberg, R. B., Dantzker, C. \& Patton, C. S. (1990). Sensitivity of serum apolipoprotein A-IV levels to changes in dietary fat content. Gastroenterology 98, 17-24.

Welch, I., Saunders, K. \& Read, N. W. (1985). Effect of ileal and intravenous infusions of fat emulsions on feeding and satiety in human volunteers. Gastroenterology 89, 1293-1297.

Zimmet, P. (1992). Kelly West Lecture 1991. Challenges in diabetes epidemiology - from West to the rest. Diabetes Care 15, 232-252. 